Article

\title{
Stereoselective Syntheses and Application of Chiral Bi- and Tridentate Ligands Derived from (+)-Sabinol
}

\author{
Yerbolat Tashenov ${ }^{1}$, Mathias Daniels ${ }^{2}$ (D), Koen Robeyns ${ }^{3}$ (D), Luc Van Meervelt ${ }^{2}$ (D), \\ Wim Dehaen ${ }^{2}$, Yerlan M. Suleimen ${ }^{1}$ and Zsolt Szakonyi ${ }^{4,5, *}$ \\ 1 Institute of Applied Chemistry, Chemistry Department of L.N. Gumilyov Eurasian National University, \\ Munaitpassov st., 5, 010008 Astana, The Republic of Kazakhstan; tashenov_yeo@edu.enu.kz (Y.T.); \\ Suleimen_em@enu.kz (Y.M.S.) \\ 2 KU Leuven, Department of Chemistry, Celestijnenlaan 200F, B-3001 Leuven, Belgium; \\ mathias.daniels@kuleuven.be (M.D.); luc.vanmeervelt@kuleuven.be (L.V.M.); \\ wim.dehaen@kuleuven.be (W.D.) \\ 3 IMCN, Molecules Solids and Reactivity division (MOST), Université catholique de Louvain, Place Pasteur 1, \\ B-1348 Louvain-la-Neuve, Belgium; koen.robeyns@uclouvain.be \\ 4 Institute of Pharmaceutical Chemistry, University of Szeged, Eötvös u. 6, H-6720 Szeged, Hungary \\ 5 Interdisciplinary Centre of Natural Products, University of Szeged, H-6720 Szeged, Hungary \\ * Correspondence: szakonyi@pharm.u-szeged.hu; Tel.: +36-62-546-809 \\ Academic Editors: Laura Palombi and Antonio Massa \\ Received: 13 February 2018; Accepted: 22 March 2018; Published: 27 March 2018

\begin{abstract}
A library of bidentate diols, as well as tridentate triols and aminodiols, derived from $(+)$-sabinol, was synthesized in a stereoselective manner. Sabinol was transformed into allylic trichloroacetamide via Overman rearrangement of the corresponding trichloroacetimidate. After changing the protecting group to Boc, the enamine was subjected to stereospecific dihydroxylation with $\mathrm{OsO}_{4} / \mathrm{NMO}$, resulting in the $(1 R, 2 R, 3 R, 5 R)$-aminodiol diastereomer. The obtained primary aminodiol was transformed to a secondary analogue. The ring closure of the $\mathrm{N}$-benzyl-substituted aminodiol with formaldehyde was investigated and regioselective formation of the spiro-oxazolidine ring was observed. Hydroboration or dihydroxylation of sabinol or its benzyl ether with $\mathrm{OsO}_{4} / \mathrm{NMO}$ resulted in the formation of sabinane-based diols and triols following a highly stereospecific reaction. Treatment of sabinol with $m$-CPBA afforded O-benzoyl triol as a diastereoisomer of the directly dihydroxylated product, instead of the expected epoxy alcohol. The resulting aminodiols, diol, and triols were applied as chiral catalysts in the reaction of diethylzinc and benzaldehyde from moderate to good selectivity.
\end{abstract}

Keywords: sabinol; terpenoid; catalyst; chiral ligand; triol; aminodiol; asymmetric catalysis

\section{Introduction}

In recent years, the discovery and application of new chiral auxiliaries and catalysts have become a crucial question in stereoselective syntheses [1-4]. To achieve new, efficient, and commercially available chiral catalysts, natural chiral terpenes [5], including (+)-pulegone [6-8], $\alpha$ - and $\beta$-pinene [9-14], and fenchone-camphor [15-19] have proved to be excellent sources. Starting from these readily available natural sources, several powerful chiral catalysts, including various di- and trifunctional synthons, such as 1,3-aminoalcohols and aminodiols, have been applied in stereoselective syntheses $[5,20]$.

Besides their importance in enantioselective catalysis, 3-amino-1,2-diols are good starting materials for the synthesis of various heterocyclic ring systems, such as 1,3-oxazines or oxazolidines [8,11,21-25]. Several mono- or bicyclic aminodiol derivatives possess remarkable biological activity. The Abbott 
aminodiol was also found to be a useful building block for the synthesis of the potent renin inhibitor Zankiren [26]. Some 3-amino-1,2-diols have been investigated as selective antagonists on receptor

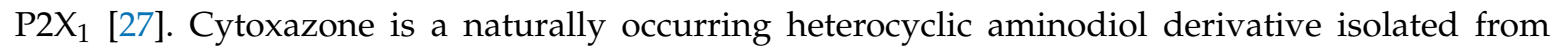
Streptomyces species $[28,29]$, and expresses cytokine modulator activity by inhibiting the signaling pathway of Th2 cells [30,31]. Some bicyclic aminodiol-based carbocyclic nucleoside analogues exert antiviral activity [32].

Monoterpene-based diols or triols have also proved to be easily available, good chiral auxiliaries and catalysts [33,34]. Some of the terpenoid diols also possess marked biological, e.g., antimicrobial, antifungal or enzyme inhibitor activities [35-37].

Similar to pinane- and carane-based allylic alcohols, (+)-sabinol and its acetate are available from the essential oil of several plants e.g., Juniperus sabina L. in a large scale [38-40]. Although this interesting monoterpene derivative has been intensively studied from the biological point of view, it was scarcely investigated for its chemical transformations [41].

Our present aim was to synthesize a library of sabinane-based chiral di- and trifunctional synthons, such as 3-amino-1,2-diols, diols, and triols starting from (+)-sabinol, achieved from a natural source. We also decided to evaluate the resulting synthons as catalysts in the asymmetric addition of $\mathrm{Et}_{2} \mathrm{Zn}$ to benzaldehyde. The planned aminodiols, diols, and triols may serve as useful building blocks for the synthesis of new heterocyclic ring systems and biologically active compounds.

\section{Results}

\subsection{Synthesis and Transformations of Sabinol-Based 3-Amino-1,2-Diols}

(+)-Sabinol 1, the key starting material, was isolated from the essential oil of Juniperus sabina L. according to the literature procedure, and its purity was found to be $>98 \%$ based on GC analysis [38-40].

Sabinol was transformed into trichloroacetimidate $\mathbf{2}$ in the presence of trichloroacetonitrile and DBU as a strong base (Scheme 1) [8,11]. 2 underwent Overman rearrangement by heating in the presence of $\mathrm{K}_{2} \mathrm{CO}_{3}$, resulting in protected allylamine 3 [42]. Since we have found difficulties during the deprotection of $\mathrm{N}$-trichloroacetyl aminodiols in our recent studies [8], we have changed the protecting group to $\mathrm{Boc}$ in a two-step process via enamine 4. Stereospecific dihydroxylation of 5, applying $\mathrm{OsO}_{4}$ as the catalyst and NMO as the oxidant, produced protected $(1 R, 2 R, 3 R, 5 R)$-aminodiol $\mathbf{6}$ as a single diastereomer (based on the ${ }^{1} \mathrm{H}$ NMR study of the crude product). Acid-catalyzed removal of the protecting group resulted in primary aminodiol hydrochloride 7 with $41 \%$ overall yield.
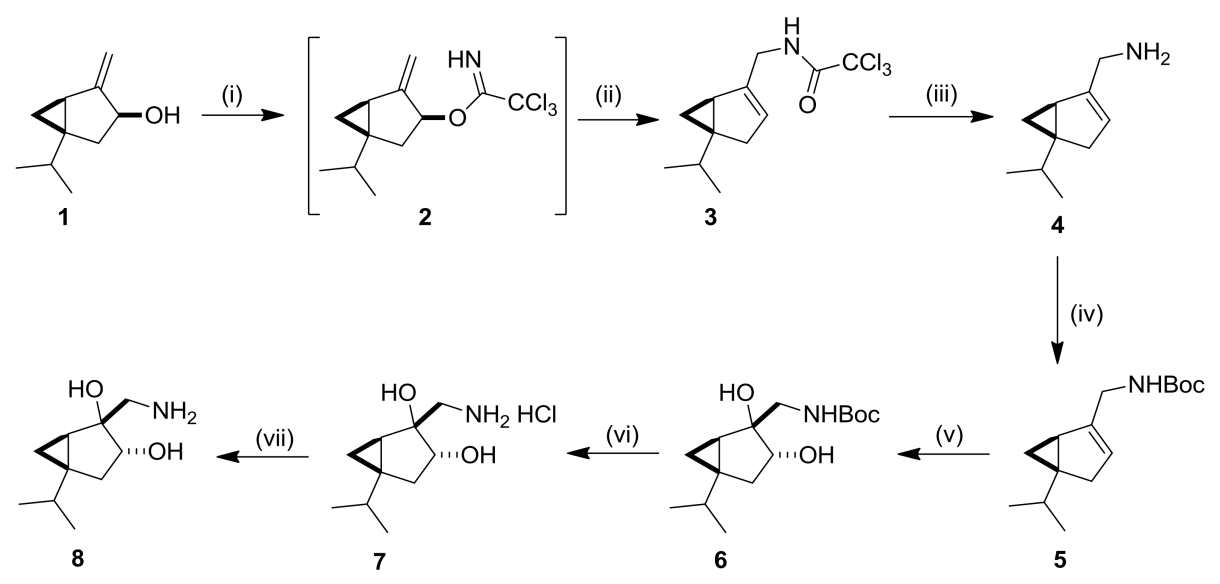

Scheme 1. Reagents and conditions: (i) $\mathrm{CCl}_{3} \mathrm{CN}, \mathrm{DBU}$, dry $\mathrm{CH}_{2} \mathrm{Cl}_{2}, \mathrm{rt}, 2 \mathrm{~h}$; (ii) anhydrous $\mathrm{K}_{2} \mathrm{CO}_{3}$, dry xylene, reflux, 12 h, 77\%; (iii) $2 \mathrm{~N}$ aq NaOH, EtOH, rt, 2 h, 72\%; (iv) Boc $2 \mathrm{O}$, TEA, DMAP, THF, rt, $22 \mathrm{~h}, 95 \%$; (v) $\mathrm{OsO}_{4}, \mathrm{NMO}$, acetone $/ \mathrm{H}_{2} \mathrm{O}, \mathrm{rt}, 12 \mathrm{~h}, 93 \%$; (vi) $5 \%$ aq $\mathrm{HCl}, \mathrm{Et}_{2} \mathrm{O}, \mathrm{rt}, 24 \mathrm{~h}, 77 \%$; (vii) 15\% aq $\mathrm{KOH}, \mathrm{CH}_{2} \mathrm{Cl}_{2}, \mathrm{rt}, 83 \%$. 
The relative configuration of $\mathbf{6}$ was determined by NOESY spectral analysis. Clear NOE correlations were observed between Me of the isopropyl group at position 5 and $\mathrm{H}-1, \mathrm{OH}-2$, as well as between H-6 and H-3, $\mathrm{CH}_{2}$ NHBoc. Therefore, the structure of 6 was assigned as shown in Figure 1.

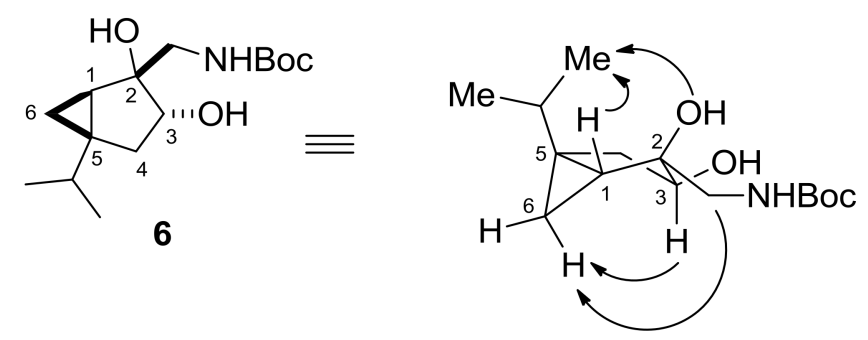

Figure 1. Determination of the relative configuration of 6 by NOESY.

Aminodiol 8 was transformed to $N$-benzyl derivative 9 by reductive alkylation via condensation with benzaldehyde, followed by subsequent reduction with sodium borohydride (Scheme 2). Next, the regioselectivity of the ring closure of $\mathbf{9}$ with formaldehyde was investigated. The reaction has proved to be highly regioselective, resulting only in spiro-oxazolidine 10, while the fused 1,3-oxazine structure could not be detected from the crude product by means of ${ }^{1} \mathrm{H}$ NMR spectroscopy. This observation shows similarity with earlier results we have obtained after ring closure of pinane-based 3-amino-1,2-diols [23], and it is in contrast with those of carane-based analogues [24,25].

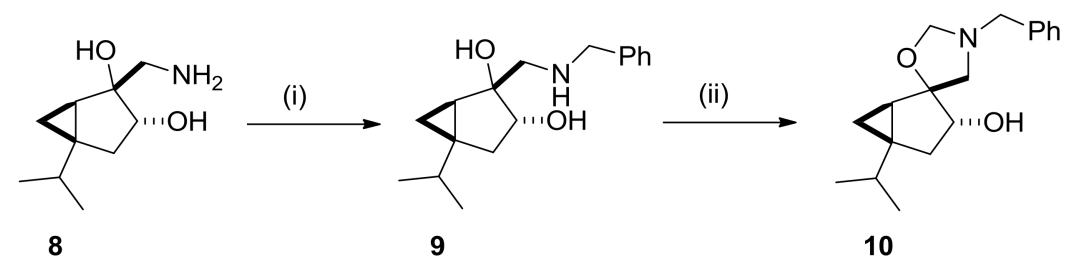

Scheme 2. Reagents and conditions: (i) $\mathrm{PhCHO}$, dry EtOH, $2 \mathrm{~h}$, then $\mathrm{NaBH}_{4}, \mathrm{EtOH}, 48 \mathrm{~h}, \mathrm{rt}, 56 \%$; (ii) $35 \%$ aq $\mathrm{CH}_{2} \mathrm{O}, \mathrm{Et}_{2} \mathrm{O}, \mathrm{rt}, 1 \mathrm{~h}, 90 \%$.

\subsection{Synthesis and Transformations of Sabinol-Based Diols and Triols}

Since monoterpenic diols and triols might serve as chiral catalysts or could be used as excellent starting materials for the synthesis of more complex 1,3-heterocycles [34,43], we decided to explore the preparation and some transformations of sabinane-based diols and triols starting from (+)-sabinol 1.

Hydroboration reaction of 1 with $\mathrm{BH}_{3}$. THF or $\mathrm{BH}_{3} \cdot \mathrm{Me}_{2} \mathrm{~S}$ followed by treatment with $\mathrm{H}_{2} \mathrm{O}_{2}$ resulted in cis bicyclic diol 11 in a highly stereospecific reaction (Scheme 3). Beside the NOESY spectral structural analysis, the relative configuration of $\mathbf{1 1}$ was determined by X-ray crystallography (Figure 2).

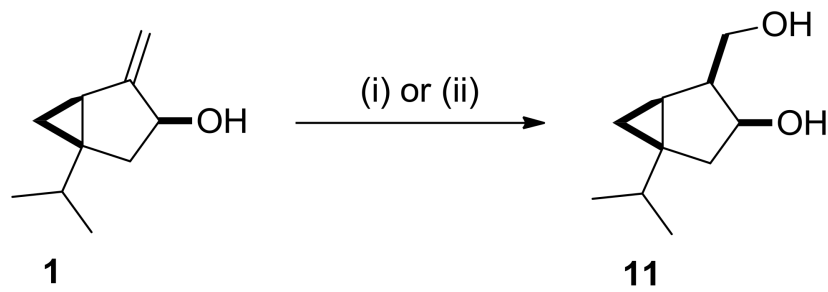

Scheme 3. (i) $\mathrm{BH}_{3} \cdot \mathrm{THF}, \mathrm{THF}, 0{ }^{\circ} \mathrm{C}$ to $\mathrm{rt}, 2.5 \mathrm{~h}$, then $\mathrm{NaOH} / \mathrm{H}_{2} \mathrm{O}_{2} / \mathrm{H}_{2} \mathrm{O}, \mathrm{THF}, \mathrm{rt}, 30 \mathrm{~min}, 47 \%$; (ii) $\mathrm{BH}_{3} \cdot \mathrm{Me}_{2} \mathrm{~S}, \mathrm{THF}, 0{ }^{\circ} \mathrm{C}$ to rt, $18 \mathrm{~h}$, then $\mathrm{NaOH} / \mathrm{H}_{2} \mathrm{O}_{2} / \mathrm{H}_{2} \mathrm{O}$, THF, rt, $30 \mathrm{~min}, 70 \%$.

The planes of the two rings in 11 make an angle of $76.90(14)^{\circ}$. The cyclopentane ring has an envelope conformation with atom $\mathrm{C} 1$ as the tip. The substituent O6-H6 occupies an axial position on 
the envelope tip, whereas the isopropyl and O8-H8 substituents are in equatorial positions. In the crystal packing, both hydroxyl groups are involved in hydrogen bonds [O6 .. O $8(-1 / 2+x,-1 / 2-y$, $1-z)=2.6796(18) \AA$, O8 . . O6 $(1+x, y, z)=2.7223(16) \AA]$, resulting in a double chain of molecules running in the $a$-axis direction (Figure $\mathrm{S} 1$ ).

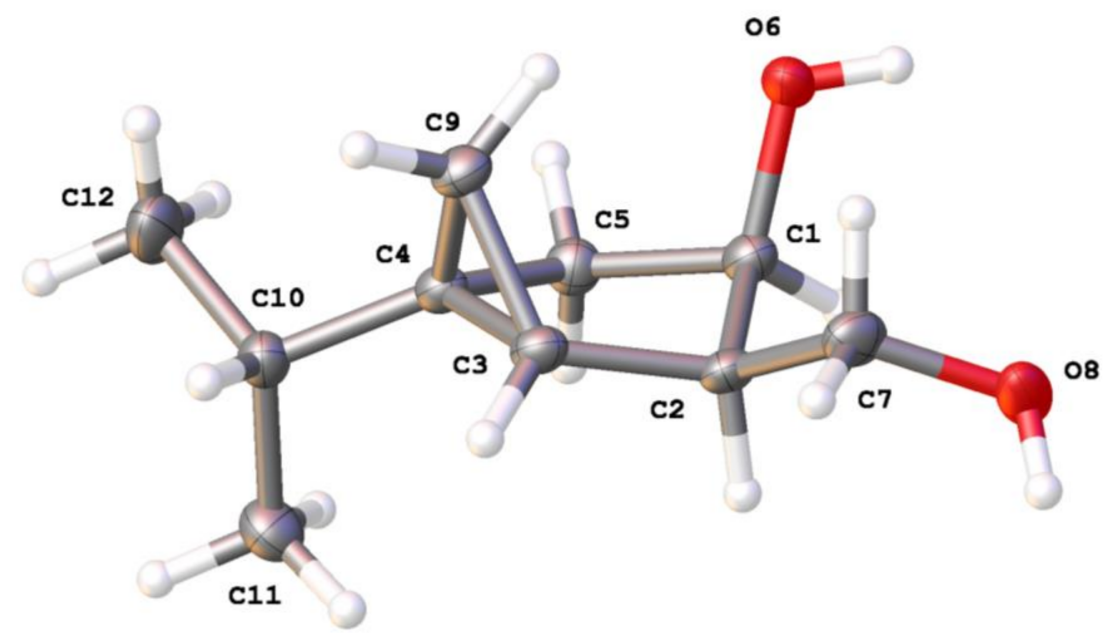

Figure 2. Crystal structure of compound 11. Thermal ellipsoids are drawn at the $50 \%$ probability level.

The synthesis of sabinane-based triols also started from 1. (+)-Sabinol was treated with the $\mathrm{OsO}_{4} / \mathrm{NMO}$ system providing triol 13 in a highly stereospecific reaction. In order to compare the catalytic importance of hydroxyl functions, O-benzyl derivative $\mathbf{1 4}$ was also prepared via benzylation of $\mathbf{1}$ with benzyl bromide, followed by stereospecific dihydroxylation (Scheme 4).

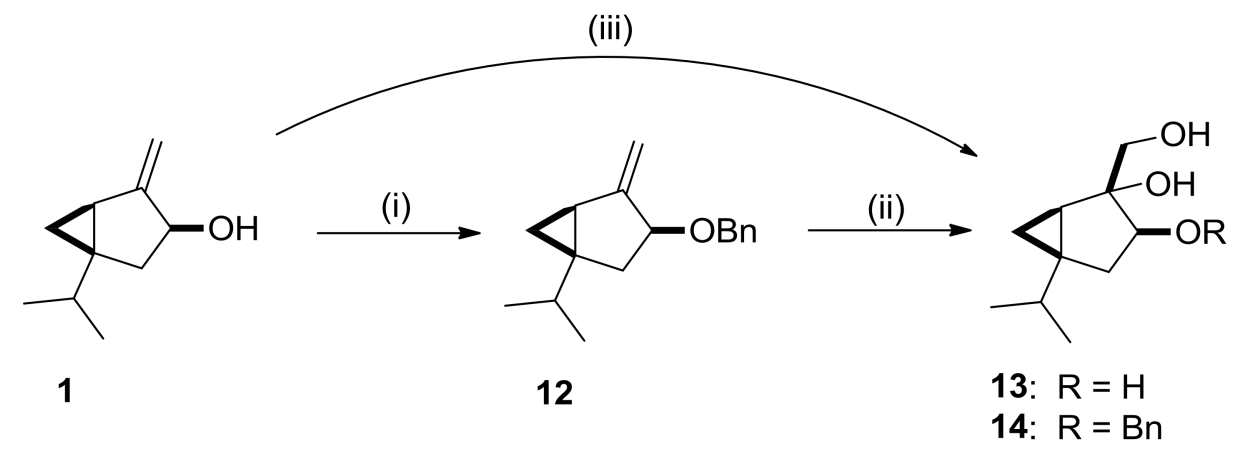

Scheme 4. (i) $\mathrm{BnBr}, \mathrm{NaH}$, THF, reflux, $1 \mathrm{~h}, 92 \%$; (ii) $\mathrm{OsO}_{4}, \mathrm{NMO}$, acetone $/ \mathrm{H}_{2} \mathrm{O}, \mathrm{rt}, 12 \mathrm{~h}, 44 \%$; (ii) $\mathrm{OsO}_{4}$, $\mathrm{NMO}$, acetone $/ \mathrm{H}_{2} \mathrm{O}, \mathrm{rt}, 12 \mathrm{~h}, 81 \%$.

Treatment of sabinol 1 with $m$-CPBA did not yield the desired epoxide 15. Rather, the generated epoxide underwent an in situ ring-opening process after the electrophilic attack of the formed $m$-chlorobenzoic acid, resulting in ester 17 (Scheme 5) [44-46]. The intermediate epoxide could not be isolated even after applying miscellaneous conditions, such as varying temperature, $\mathrm{NaHCO}_{3}$ or $\mathrm{Na}_{2} \mathrm{CO}_{3}$, or buffer solutions. 17 easily underwent acyl migration under the applied conditions, affording its structural isomer 18. Interesting to note that while under slightly alkaline work up conditions (sat. $\mathrm{NaHCO}_{3}$ solution) only isomer 18 was isolated, applying strong alkaline conditions (10\% $\mathrm{NaOH}$ solution), the mixture of two regioisomers was isolated. Acyl migration of the pure products could also be observed during ${ }^{13} \mathrm{C} \mathrm{NMR}$ analysis in $\mathrm{CDCl}_{3}$ solution. It must be mentioned that Garside et al. reported a similar reaction of sabinol with peracetic acid; however, they observed ring rearrangement and formation of acetyl p-menthane-1,2,4-triol [47]. 


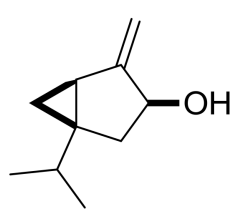

1

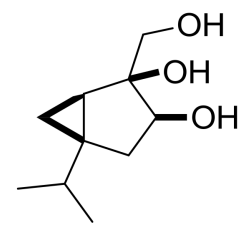

19
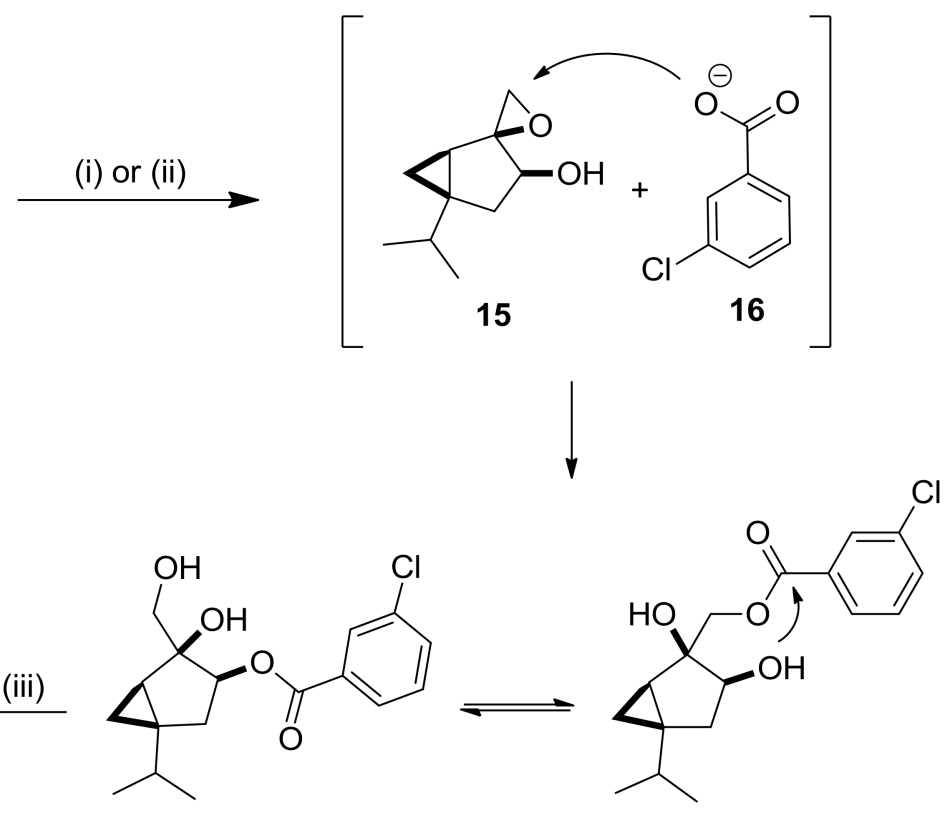

18

17

Scheme 5. (i) $m$-CPBA, $\mathrm{CH}_{2} \mathrm{Cl}_{2}, \mathrm{Na}_{2} \mathrm{HPO}_{4}$ buffer sol., ( $\left.\mathrm{pH}=9.2\right)$, rt, $1 \mathrm{~h}$, work up with $10 \% \mathrm{NaOH} / \mathrm{H}_{2} \mathrm{O}$, $37 \%$ (mixture of 17 and 18); (ii) $m$-CPBA, $\mathrm{CH}_{2} \mathrm{Cl}_{2}, \mathrm{Na}_{2} \mathrm{HPO}_{4}$. buffer sol. (pH = 9.2), rt, $1 \mathrm{~h}$, work up with sat. $\mathrm{NaHCO}_{3} / \mathrm{H}_{2} \mathrm{O}, 38 \%$ (18); (iii) $10 \% \mathrm{NaOH} / \mathrm{H}_{2} \mathrm{O}, \mathrm{EtOH}, \mathrm{rt}, 30 \mathrm{~min}, 91 \%$.

The regioisomeric relation of $\mathbf{1 7}$ and $\mathbf{1 8}$ was determined by their hydrolysis under alkaline conditions, which furnished stereohomogenic compound 19, whereas the relative configuration of 19 was assigned by NOESY spectral structural analysis and 19 was found to be a diastereoisomer of triol 13.

\subsection{Application of Sabinol-Based Aminodiol, Diol and Triol Derivatives as Chiral Ligands in the} Enantioselective Addition of Diethylzinc to Benzaldehyde

Application of the prepared 3-amino-1,2-diols (8-10), 1,3-diol (11), and triols (13,14 and 17-19) as catalysts in the ethylation of benzaldehyde resulted in 1-phenyl-1-propanol enantiomers 21 and 22 (Scheme 6).<smiles>CC(=O)c1ccccc1</smiles>

20

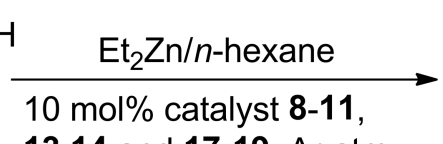
13,14 and 17-19, Ar atm., rt, $74-93 \%$<smiles>CC[C@@H](O)c1ccccc1</smiles>

21: $(\mathrm{R})$<smiles>CCC(O)c1ccccc1</smiles>

22: (S)

Scheme 6. Catalyzed addition of diethylzinc to benzaldehyde.

The enantiomeric purity of the secondary alcohol obtained was determined by HPLC analysis [7]. Catalysts were applied in $10 \%$ molar ratio and reactions were carried out in $n$-hexane at room temperature. The results are presented in Table 1. 
Table 1. Addition of diethylzinc to benzaldehyde, catalyzed by various types of diol, triols, and aminodiols at room temperature.

\begin{tabular}{|c|c|c|c|c|}
\hline Entry & Catalyst (10 mol \%) & Yield $^{1}(\%)$ & $e e^{2}(\%)$ & Config. of Major Product ${ }^{3}$ \\
\hline 1 & 8 & 88 & 44 & $S$ \\
\hline 2 & 9 & 98 & 66 & $S$ \\
\hline 3 & 10 & 98 & 58 & $S$ \\
\hline 4 & 11 & 73 & 6 & $S$ \\
\hline 5 & 13 & 88 & 12 & $S$ \\
\hline 6 & 14 & 87 & 17 & $S$ \\
\hline 7 & 17 & 73 & 9 & $S$ \\
\hline 8 & 18 & 95 & 4 & $S$ \\
\hline 9 & 19 & 81 & 8 & $S$ \\
\hline
\end{tabular}

1 Yields after silica column chromatography. ${ }^{2}$ Determined on the crude product by HPLC (Chiracel OD-H).

${ }^{3}$ Determined by comparing the $t_{\mathrm{R}}$ of the HPLC analysis and the optical rotation with the literature data [7].

In the addition of $\mathrm{Et}_{2} \mathrm{Zn}$ in $n$-hexane solution to benzaldehyde, diol 11, or triols 13, 14, and 17-19 afforded the corresponding alcohols with low enantioselectivities. The stereoselectivity could not be improved either by changing the solvent to toluene or lowering the reaction temperature. Increased, but still moderate asymmetric induction was observed when aminodiol derivatives 8-10 were used. The formation of $S$ enantiomer 22 was predominant in all cases.

\section{Experimental Section}

\subsection{Materials and Methods}

${ }^{1} \mathrm{H}$ and ${ }^{13} \mathrm{C}$ NMR spectra were recorded on a Bruker Avance DRX 300 and 500 spectrometer $[\delta=0$ (TMS)] (Bruker Corp., Billerica, MA, USA) in the solvents indicated. Chemical shifts are expressed in ppm ( $\delta$ ) relative to TMS as internal reference. $J$ values are given in Hz. Elemental analyses were performed on a Perkin-Elmer 2400 Elemental Analyzer (PerkinElmer Inc., Waltham, MA, USA). Chiral HPLC analysis was performed without derivatization by JASCO LC-4000 system on a Chiralcel OD-H column $(250 \times 4.6 \mathrm{~mm}$, Jasco Europe S.R.L., Cremella, Italy). UV detection was monitored at $215 \mathrm{~nm}$. Optical rotations were obtained with a Perkin-Elmer 341 polarimeter (PerkinElmer Inc., Shelton, CT, USA). Melting points were determined on a Kofler apparatus (Nagema, Dresden, Germany) and are uncorrected. Chromatographic separations were carried out on Merck Kieselgel 60 (230-400 mesh ASTM, Merck Ltd., Budapest, Hungary). Reactions were monitored with Merck Kieselgel 60 F254-precoated TLC plates ( $0.25 \mathrm{~mm}$ thickness). All chemicals and solvents were used as supplied.

Sabinol 1 was isolated from the essential oil of Juniperus sabina L. according to a literature process [38-40].

Synthesis of 2,2,2-trichloro-N-(((1R,5S)-5-isopropylbicyclo[3.1.0]hex-2-en-2-yl)methyl)acetamide (3). To a solution of sabinol $1(4.00 \mathrm{~g}, 26.27 \mathrm{mmoL})$ in dry $\mathrm{CH}_{2} \mathrm{Cl}_{2}(50 \mathrm{~mL})$ 1,8-diazabicycloundec-7-ene $(2 \mathrm{~mL}$, $13.39 \mathrm{mmoL})$ and $\mathrm{CCl}_{3} \mathrm{CN}(4.68 \mathrm{~mL}, 46.67 \mathrm{mmoL})$ were added at $0{ }^{\circ} \mathrm{C}$. The reaction mixture was then allowed to warm to room temperature and stirred for $2 \mathrm{~h}$. When the reaction was completed (monitored by means of TLC), the mixture was concentrated to a volume of $20 \mathrm{~mL}$ and then filtered through a short pad of silica gel, washing with $\mathrm{CH}_{2} \mathrm{Cl}_{2}$. Evaporation of the solvent in vacuum gave a brown oil, which was immediately dissolved in dry xylene $(200 \mathrm{~mL})$. To this solution, anhydrous $\mathrm{K}_{2} \mathrm{CO}_{3}(1.00 \mathrm{~g}, 7.23 \mathrm{mmoL})$ was added, and the mixture was treated at reflux temperature overnight. The obtained solution was then filtered through a Celite pad, washed, and concentrated under reduced pressure. The obtained crude product was purified by column chromatography on silica gel $\left(\mathrm{R}_{\mathrm{f}}=0.52\right.$; n-hexane $/$ EtOAc $=9 / 1$ ).

Compound 3: $6.03 \mathrm{~g}(77 \%)$; pale-yellow crystalline powder; mp: $45-47^{\circ} \mathrm{C} ;[\alpha]_{\mathrm{D}}^{20}=+7(c=0.250$; $\mathrm{MeOH}) .{ }^{1} \mathrm{H}$ NMR $\left(300 \mathrm{MHz}, \mathrm{CDCl}_{3}\right) \delta(\mathrm{ppm}): 0.08(1 \mathrm{H}, \mathrm{t}, J=3.4 \mathrm{~Hz}), 0.84(1 \mathrm{H}, \mathrm{dd}, J=3.8,7.5 \mathrm{~Hz}), 0.90$ 
$(3 \mathrm{H}, \mathrm{d}, J=6.9 \mathrm{~Hz}), 0.95(3 \mathrm{H}, \mathrm{d}, J=6.8 \mathrm{~Hz}), 1.39-1.52(2 \mathrm{H}, \mathrm{m}), 2.25(1 \mathrm{H}, \mathrm{d}, J=17.7 \mathrm{~Hz}), 2.45(1 \mathrm{H}, \mathrm{dd}$, $J=2.2,17.7 \mathrm{~Hz}), 3.98-4.16(2 \mathrm{H}, \mathrm{m}), 5.26(1 \mathrm{H}, \mathrm{s}), 6.79(1 \mathrm{H}, b r \mathrm{~s}) .{ }^{13} \mathrm{C} \mathrm{NMR}\left(75 \mathrm{MHz}, \mathrm{CDCl}_{3}\right) \delta(\mathrm{ppm})$ : 19.9, 20.2, 21.8, 28.4, 32.8, 34.0, 36.4, 41.8, 92.9, 124.0, 144.1, 161.8. Anal. Calcd for $\mathrm{C}_{12} \mathrm{H}_{16} \mathrm{Cl}_{3} \mathrm{NO}$ : $\mathrm{C}$ 48.59; H 5.44; $\mathrm{Cl} 35.86 ; \mathrm{N}$ 4.72. Found: C 48.65; H 5.52; Cl 35.63; N 4.68.

Synthesis of ((1R,5S)-5-isopropylbicyclo[3.1.0]hex-2-en-2-yl)methanamine (4). A solution of acetamide 3 $(5.95 \mathrm{~g}, 20 \mathrm{mmoL})$ in ethanol $(30 \mathrm{~mL})$ was stirred with $2 \mathrm{~N}$ aqueous $\mathrm{NaOH}$ solution $(30 \mathrm{~mL})$ at room temperature for $2 \mathrm{~h}$. The reaction mixture was then concentrated to an aqueous residue which was extracted with $\mathrm{CH}_{2} \mathrm{Cl}_{2}(3 \times 30 \mathrm{~mL})$. The organic layer was dried $\left(\mathrm{Na}_{2} \mathrm{SO}_{4}\right)$ and evaporated to dryness. Compound 4 was used without further purification.

Compound 4: $2.18 \mathrm{~g}(72 \%)$; yellow oil; $[\alpha]_{\mathrm{D}}^{20}=-5(c=0.250 ; \mathrm{MeOH}) .{ }^{1} \mathrm{H}$ NMR $\left(500 \mathrm{MHz}, \mathrm{CDCl}_{3}\right)$ $\delta(\mathrm{ppm}): 0.05(1 \mathrm{H}, \mathrm{t}, J=3.2 \mathrm{~Hz}), 0.80(1 \mathrm{H}, \mathrm{dd}, J=3.5,7.5 \mathrm{~Hz}), 0.90(3 \mathrm{H}, \mathrm{d}, J=6.8 \mathrm{~Hz}), 0.95(3 \mathrm{H}, \mathrm{d}$, $J=6.8 \mathrm{~Hz}), 1.41-1.47(4 \mathrm{H}, \mathrm{m}), 2.22(1 \mathrm{H}, \mathrm{d}, J=17.3 \mathrm{~Hz}), 2.41(1 \mathrm{H}, \mathrm{dd}, J=2.0,17.3 \mathrm{~Hz}), 3.37(2 \mathrm{H}, \mathrm{dd}$, $J=15.4,15.6 \mathrm{~Hz}), 5.13(1 \mathrm{H}, \mathrm{s}) .{ }^{13} \mathrm{C} \mathrm{NMR}\left(125.8 \mathrm{MHz}, \mathrm{CDCl}_{3}\right) \delta(\mathrm{ppm}): 19.8,20.1,21.7,28.7,32.8,33.7$, 36.4, 42.7, 120.0, 151.2. Anal. Calcd for $\mathrm{C}_{10} \mathrm{H}_{17} \mathrm{~N}$ : C 79.41; H 11.33; N 9.26. Found: C 79.63; H 11.45; N 9.01 .

Synthesis of tert-butyl (((1R,5S)-5-isopropylbicyclo[3.1.0]hex-2-en-2-yl)methyl)carbamate (5). To a solution of 4 (2.00 g, $13.22 \mathrm{mmoL})$ TEA (3.34 g, $33.05 \mathrm{mmoL})$, DMAP $(0.16 \mathrm{~g}, 1.32 \mathrm{mmoL})$ in THF (100 mL) and $\mathrm{Boc}_{2} \mathrm{O}(3.17 \mathrm{~g}, 14.54 \mathrm{mmoL})$ were added at room temperature. The reaction mixture was stirred for $22 \mathrm{~h}$ and then concentrated under reduced pressure. The crude product was purified by column chromatography on silica gel $\left(\mathrm{R}_{\mathrm{f}}=0.50\right.$; $\mathrm{n}$-hexane $/$ EtOAc $\left.=9 / 1\right)$.

Compound 5: $3.16 \mathrm{~g}$ (95\%); pale-yellow oil; $[\alpha]_{\mathrm{D}}^{20}=+6(c=0.250 ; \mathrm{MeOH}) .{ }^{1} \mathrm{H}$ NMR $(500 \mathrm{MHz}$, $\left.\mathrm{CDCl}_{3}\right) \delta(\mathrm{ppm}): 0.04(1 \mathrm{H}, \mathrm{t}, J=3.1 \mathrm{~Hz}), 0.80(1 \mathrm{H}, \mathrm{dd}, J=3.7,7.5 \mathrm{~Hz}), 0.89(3 \mathrm{H}, \mathrm{d}, J=6.8 \mathrm{~Hz}), 0.94(3 \mathrm{H}$, $\mathrm{d}, J=6.7 \mathrm{~Hz}), 1.44-1.47(2 \mathrm{H}, \mathrm{m}), 1.45(9 \mathrm{H}, \mathrm{s}), 2.21(1 \mathrm{H}, \mathrm{d}, J=17.5 \mathrm{~Hz}), 2.40(1 \mathrm{H}, \mathrm{dd}, J=2.0,17.4 \mathrm{~Hz})$, $3.81(2 \mathrm{H}, \mathrm{s}), 4.59(1 \mathrm{H}, b r \mathrm{~s}), 5.15(1 \mathrm{H}, \mathrm{s}) .{ }^{13} \mathrm{C} \mathrm{NMR}\left(125.8 \mathrm{MHz}, \mathrm{CDCl}_{3}\right) \delta(\mathrm{ppm}): 19.8,20.1,21.6,28.4$, 28.4, 32.7, 33.7, 36.3, 41.1, 79.2, 122.1, 146.3, 155.9. Anal. Calcd for $\mathrm{C}_{15} \mathrm{H}_{25} \mathrm{NO}_{2}$ : C 71.67; $\mathrm{H} 10.02 ; \mathrm{N} 5.57$. Found: C 71.88; H 10.20; N 5.41.

Synthesis of tert-butyl (( $(1 R, 2 R, 3 R, 5 R)-2,3$-dihydroxy-5-isopropylbicyclo[3.1.0]hexan-2-yl)methyl)carbamate (6). To 5 (3.00 g, $11.93 \mathrm{mmoL})$ in acetone $(50 \mathrm{~mL})$ 4-methylmorpholine $\mathrm{N}$-oxide $(10 \mathrm{~mL}, 50 \%$ aqueous solution) and $\mathrm{OsO}_{4}(4 \mathrm{~mL}, 2 \%$ tert-BuOH solution) were added. The reaction mixture was stirred for $12 \mathrm{~h}$ at room temperature. The reaction was then quenched by the addition of saturated aqueous $\mathrm{Na}_{2} \mathrm{SO}_{3}(50 \mathrm{~mL})$ and extracted with EtOAc $(3 \times 50 \mathrm{~mL})$. The combined organic phase was dried $\left(\mathrm{Na}_{2} \mathrm{SO}_{4}\right)$ and evaporated, then the crude residue was purified by column chromatography $\left(\mathrm{R}_{\mathrm{f}}=0.43\right.$; n-hexane $/$ EtOAc $=1: 1$ ).

Compound 6: $3.16 \mathrm{~g}(93 \%)$; off-white crystalline powder; $\mathrm{mp}: 68-70{ }^{\circ} \mathrm{C} ;[\alpha]_{\mathrm{D}}^{20}=+38(c=0.250$; $\mathrm{MeOH}) .{ }^{1} \mathrm{H}$ NMR $\left(500 \mathrm{MHz}, \mathrm{CDCl}_{3}\right) \delta(\mathrm{ppm}): 0.30(1 \mathrm{H}, \mathrm{dd}, J=3.9,5.4 \mathrm{~Hz}), 0.38-0.44(1 \mathrm{H}, \mathrm{m}), 0.88(3 \mathrm{H}$, $\mathrm{d}, J=6.9 \mathrm{~Hz}), 0.97(3 \mathrm{H}, \mathrm{d}, J=6.8 \mathrm{~Hz}), 1.19(1 \mathrm{H}, \mathrm{dd}, J=3.6,8.5 \mathrm{~Hz}), 1.34(1 \mathrm{H}$, quint,$J=6.8 \mathrm{~Hz}), 1.45(9 \mathrm{H}$, s), $1.66(1 \mathrm{H}, \mathrm{dd}, J=9.6,11.5 \mathrm{~Hz}), 2.05(1 \mathrm{H}, \mathrm{dd}, J=7.3,12.2 \mathrm{~Hz}), 3.22(1 \mathrm{H}, \mathrm{dd}, J=6.8,14.2 \mathrm{~Hz}), 3.30(1 \mathrm{H}$, $\mathrm{dd}, J=5.2,14.3 \mathrm{~Hz}), 3.58(1 \mathrm{H}, \mathrm{t}, J=8.1 \mathrm{~Hz}), 5.03(1 \mathrm{H}, b r \mathrm{~s}) .{ }^{13} \mathrm{C}$ NMR $\left(125.8 \mathrm{MHz}, \mathrm{CDCl}_{3}\right) \delta(\mathrm{ppm}): 13.3$, 19.7, 19.8, 28.4, 28.9, 31.3, 32.6, 34.4, 47.0, 73.3, 79.1, 80.0. Anal. calcd for $\mathrm{C}_{15} \mathrm{H}_{27} \mathrm{NO}_{4}$ : C 63.13; $\mathrm{H} 9.54$; N 4.91. Found: C 63.29; H 9.65; N 4.73.

Synthesis of $(1 R, 2 R, 3 R, 5 R)$-2-aminomethyl-5-isopropylbicyclo[3.1.0]hexane-2,3-diol hydrochloride (7). A solution of $6(1.20 \mathrm{~g}, 4.20 \mathrm{mmoL})$ in $\mathrm{Et}_{2} \mathrm{O}(30 \mathrm{~mL})$ was stirred with $30 \mathrm{~mL}$ of $5 \%$ aqueous $\mathrm{HCl}$ at room temperature. After $24 \mathrm{~h}$, the two phases were separated, the aqueous phase was washed with $\mathrm{Et}_{2} \mathrm{O}(3 \times 30 \mathrm{~mL})$ and then evaporated to dryness. Crystals formed were thoroughly washed with $\mathrm{Et}_{2} \mathrm{O}$.

Compound 7: $0.72 \mathrm{~g}(77 \%)$; colorless crystals; mp: $146-148^{\circ} \mathrm{C} ;[\alpha]_{\mathrm{D}}^{20}=+42(c=0.250 ; \mathrm{MeOH}) .{ }^{1} \mathrm{H}$ NMR $\left(500 \mathrm{MHz}, \mathrm{D}_{2} \mathrm{O}\right) \delta(\mathrm{ppm}): 0.41(1 \mathrm{H}, \mathrm{dd}, J=3.9,5.6 \mathrm{~Hz}), 0.54-0.59(1 \mathrm{H}, \mathrm{m}), 0.85(3 \mathrm{H}, \mathrm{d}, J=6.9 \mathrm{~Hz})$, 
$0.97(3 \mathrm{H}, \mathrm{d}, J=6.8 \mathrm{~Hz}), 1.30(1 \mathrm{H}, \mathrm{dd}, J=3.6,8.5 \mathrm{~Hz}), 1.47(1 \mathrm{H}$, septet, $J=6.8 \mathrm{~Hz}), 1.75(1 \mathrm{H}, \mathrm{dd}, J=10.0$, $11.71 \mathrm{~Hz}), 2.15(1 \mathrm{H}, \mathrm{dd}, J=7.4,12.3 \mathrm{~Hz}), 3.10(2 \mathrm{H}, \mathrm{s}), 3.66(1 \mathrm{H}, \mathrm{dd}, J=7.9,8.7 \mathrm{~Hz}) .{ }^{13} \mathrm{C}$ NMR $(125.8$ $\left.\mathrm{MHz}, \mathrm{D}_{2} \mathrm{O}\right) \delta(\mathrm{ppm}): 11.8,18.6,19.1,26.7,31.6,32.0,33.2,45.0,72.8,77.0$. Anal. calcd for $\mathrm{C}_{10} \mathrm{H}_{20} \mathrm{ClNO}_{2}$ : C 54.17; H 9.09; N 6.32. Found: C 54.28; H 9.29; N 6.01.

Synthesis of (1R,2R,3R,5R)-2-((benzylamino)methyl)-5-isopropylbicyclo[3.1.0]hexane-2,3-diol (9). To a solution of aminodiol 8 liberated from $7(0.37 \mathrm{~g}, 2 \mathrm{mmoL})$ in dry ethanol $(20 \mathrm{~mL})$ benzaldehyde $(0.32 \mathrm{~g}, 3 \mathrm{mmoL})$ was added in one portion, and the solution was stirred at room temperature for $1 \mathrm{~h}$ and then evaporated to dryness. The residual product was dissolved again in dry ethanol $(20 \mathrm{~mL})$ and stirred for a further $1 \mathrm{~h}$. Next $\mathrm{NaBH}_{4}(0.23 \mathrm{~g}, 6 \mathrm{mmoL})$ was added in small portions to the mixture under ice cooling. After stirring for $48 \mathrm{~h}$, the mixture was evaporated to dryness and the residue was dissolved in $\mathrm{H}_{2} \mathrm{O}$ and extracted with $\mathrm{CH}_{2} \mathrm{Cl}_{2}(3 \times 30 \mathrm{~mL})$. The combined organic layer was dried $\left(\mathrm{Na}_{2} \mathrm{SO}_{4}\right)$, filtered and evaporated to dryness. The obtained crude product was purified by column chromatography on silica gel $\left(R_{\mathrm{f}}=0.21\right.$; toluene $/$ ethanol $\left.=4 / 1\right)$.

Compound 9: $0.31 \mathrm{~g}(56 \%)$; colorless crystals; mp: $111-113{ }^{\circ} \mathrm{C} ;[\alpha]_{\mathrm{D}}^{20}=+41(c=0.250 ; \mathrm{MeOH})$. ${ }^{1} \mathrm{H}$ NMR $\left(500 \mathrm{MHz}, \mathrm{CDCl}_{3}\right) \delta(\mathrm{ppm}): 0.22(1 \mathrm{H}, \mathrm{dd}, J=4.0,5.3 \mathrm{~Hz}), 0.32-0.36(1 \mathrm{H}, \mathrm{m}), 0.87(3 \mathrm{H}, \mathrm{d}$, $J=6.9 \mathrm{~Hz}), 0.97(3 \mathrm{H}, \mathrm{d}, J=6.8 \mathrm{~Hz}), 1.14(1 \mathrm{H}, \mathrm{dd}, J=3.7,8.5 \mathrm{~Hz}), 1.32(1 \mathrm{H}$, septet, $J=6.8 \mathrm{~Hz}), 1.63(1 \mathrm{H}$, $\mathrm{dd}, J=9.8,11.5 \mathrm{~Hz}), 2.02(1 \mathrm{H}, \mathrm{dd}, J=7.3,12.3 \mathrm{~Hz}), 2.62(1 \mathrm{H}, \mathrm{d}, J=11.9 \mathrm{~Hz}), 2.91(1 \mathrm{H}, \mathrm{d}, J=11.9 \mathrm{~Hz})$, $3.52(1 \mathrm{H}, \mathrm{t}, J=7.8 \mathrm{~Hz}), 3.79(1 \mathrm{H}, \mathrm{d}, J=13.2 \mathrm{~Hz}), 3.85(1 \mathrm{H}, \mathrm{d}, J=13.2 \mathrm{~Hz}), 7.26-7.36(5 \mathrm{H}, \mathrm{m}) .{ }^{13} \mathrm{C} \mathrm{NMR}$ $\left(125.8 \mathrm{MHz}, \mathrm{CDCl}_{3}\right.$ ) $\delta$ (ppm): 13.1, 19.6, 19.7, 29.5, 31.7, 32.8, 34.1, 54.2, 55.0, 75.0, 77.6, 127.2, 128.2, 128.5, 139.7. Anal. calcd for $\mathrm{C}_{17} \mathrm{H}_{25} \mathrm{NO}_{2}$ : C 74.14; H 9.15; N 5.09. Found: C 74.25; H 9.10; N 5.15.

Synthesis of (1R,2R,3R,5R)-3'-benzyl-5-isopropylspiro[bicyclo[3.1.0]hexane-2,5'-oxazolidin]-3-ol (10). To the solution of $9(0.15 \mathrm{~g}, 0.54 \mathrm{mmoL})$ in $\mathrm{Et}_{2} \mathrm{O}(5 \mathrm{~mL}) 35 \%$ aqueous formaldehyde solution $(2 \mathrm{~mL})$ was added. The reaction mixture was stirred for $1 \mathrm{~h}$ at room temperature, followed by making it alkaline with $10 \%$ cold aqueous $\mathrm{KOH}$ solution and extracted with $\mathrm{Et}_{2} \mathrm{O}(3 \times 20 \mathrm{~mL})$. The organic layers were combined, washed with saturated $\mathrm{NaCl}$ solution $(3 \times 20 \mathrm{~mL})$ then dried $\left(\mathrm{Na}_{2} \mathrm{SO}_{4}\right)$, filtered, and evaporated to dryness. The crude product was purified by column chromatography on silica gel $\left(R_{\mathrm{f}}=0.64 ;\right.$ toluene $/$ ethanol $\left.=4 / 1\right)$.

Compound 10: $0.14 \mathrm{~g}(90 \%)$; pale-yellow oil; $[\alpha]_{\mathrm{D}}^{20}=+63(c=0.250 ; \mathrm{MeOH}) .{ }^{1} \mathrm{H}$ NMR $(500 \mathrm{MHz}$, $\left.\left(\mathrm{CD}_{3}\right)_{2} \mathrm{SO}\right) \delta(\mathrm{ppm}): 0.27-0.32(2 \mathrm{H}, \mathrm{m}), 0.84(3 \mathrm{H}, \mathrm{d}, J=6.8 \mathrm{~Hz}), 0.93(3 \mathrm{H}, \mathrm{d}, J=6.8 \mathrm{~Hz}), 1.17-1.21(1 \mathrm{H}, \mathrm{m})$, $1.24-1.32(1 \mathrm{H}, \mathrm{m}), 1.56(1 \mathrm{H}, \mathrm{dd}, J=10.1,11.2 \mathrm{~Hz}), 1.78(1 \mathrm{H}, \mathrm{dd}, J=7.1,11.7 \mathrm{~Hz}), 2.68(1 \mathrm{H}, \mathrm{d}, J=11.0 \mathrm{~Hz})$, $2.93(1 \mathrm{H}, \mathrm{d}, J=11.0 \mathrm{~Hz}), 3.41(1 \mathrm{H}, \mathrm{dd}, J=9.4,16.8 \mathrm{~Hz}), 3.75(2 \mathrm{H}, \mathrm{s}), 4.13(1 \mathrm{H}, \mathrm{d}, J=4.5 \mathrm{~Hz}), 4.25(1 \mathrm{H}$, $\mathrm{d}, J=9.5 \mathrm{~Hz}), 4.41(1 \mathrm{H}, \mathrm{d}, J=4.4 \mathrm{~Hz}), 7.22-7.37(5 \mathrm{H}, \mathrm{m}) .{ }^{13} \mathrm{C} \mathrm{NMR}\left(125.8 \mathrm{MHz},\left(\mathrm{CD}_{3}\right)_{2} \mathrm{SO}\right) \delta(\mathrm{ppm})$ : 13.5, 20.2, 20.2, 30.5, 31.9, 32.9, 34.2, 57.9, 58.0, 74.2, 86.7, 87.3, 127.4, 128.7, 129.0, 139.8. Anal. calcd for $\mathrm{C}_{18} \mathrm{H}_{25} \mathrm{NO}_{2}$ : C 75.22; $\mathrm{H}$ 8.77; N 4.87. Found: C 75.31; H 8.91; N 4.70.

Synthesis of (1R,3S,4S,5S)-4-hydroxymethyl-1-isopropylbicyclo[3.1.0]hexan-3-ol (11). Method A: to a cooled $\left(0{ }^{\circ} \mathrm{C}\right)$ solution of sabinol $1(0.15 \mathrm{~g}, 1 \mathrm{mmoL})$ in $3 \mathrm{~mL}$ dry THF under nitrogen atmosphere, a solution of $1 \mathrm{M}$ borane THF complex $(2 \mathrm{~mL})$ was injected dropwise. After completing the addition, the mixture was allowed to warm to room temperature and stirred for $2.5 \mathrm{~h}$. After completion of hydroboration 0.5 $\mathrm{mL}$ of cold water was added and the mixture was stirred for $10 \mathrm{~min}$. This was followed by adding 0.3 $\mathrm{mL}$ of $3 \mathrm{~N}$ aqueous solution of $\mathrm{NaOH}$ and then $0.3 \mathrm{~mL}$ of $35 \% \mathrm{H}_{2} \mathrm{O}_{2}$. The mixture was stirred for an additional $30 \mathrm{~min}$, then quenched by the addition of $5 \mathrm{~mL}$ ice-cold water and extracted with EtOAc ( 3 $\times 10 \mathrm{~mL}$ ). The organic phases were collected, washed with brine, dried over $\mathrm{Na}_{2} \mathrm{SO}_{4}$ and evaporated. The residue was subjected to chromatography on silica gel $\left(R_{f}=0.21 ; n\right.$-hexane $/$ EtOAc $\left.=3 / 2\right)$.

Method B: to a cooled $\left(0{ }^{\circ} \mathrm{C}\right)$ solution of sabinol $1(0.15 \mathrm{~g}, 1 \mathrm{mmoL})$ in $5 \mathrm{~mL}$ dry THF under argon atmosphere $0.21 \mathrm{~mL}$ of $95 \%$ solution of borane dimethyl sulfide complex (BMS) in DMS was injected, then the reaction mixture was allowed to warm up to room temperature and stirred for $18 \mathrm{~h}$. The work up of the reaction mixture was the same as for Method A. 
Compound 11: Method A: $0.08 \mathrm{~g}$, (47\%); Method B: $0.12 \mathrm{~g}$ (70\%); colorless crystals; mp: $66-68{ }^{\circ} \mathrm{C}$; $[\alpha]_{\mathrm{D}}^{20}=+35(c=0.250 ; \mathrm{MeOH}) .{ }^{1} \mathrm{H}$ NMR $\left(500 \mathrm{MHz}, \mathrm{CDCl}_{3}\right) \delta(\mathrm{ppm}): 0.31-0.35(1 \mathrm{H}, \mathrm{m}), 0.85-0.89(4 \mathrm{H}$, $\mathrm{m}), 0.93(3 \mathrm{H}, \mathrm{d}, J=6.8 \mathrm{~Hz}), 0.95-0.99(1 \mathrm{H}, \mathrm{m}), 1.37(1 \mathrm{H}$, septet, $J=6.8 \mathrm{~Hz}), 1.75(1 \mathrm{H}, \mathrm{d}, J=14.1 \mathrm{~Hz}), 2.08$ $(1 \mathrm{H}, \mathrm{ddd}, J=1.4,6.8,14.2 \mathrm{~Hz}), 2.10(1 \mathrm{H}, \mathrm{s}), 2.46-2.53(1 \mathrm{H}, \mathrm{m}), 3.83(1 \mathrm{H}, \mathrm{dd}, J=9.0,10.6 \mathrm{~Hz}), 3.90(1 \mathrm{H}$, $\mathrm{dd}, J=5.5,10.7 \mathrm{~Hz}), 4.41(1 \mathrm{H}, \mathrm{t}, J=6.5 \mathrm{~Hz}) .{ }^{13} \mathrm{C} \mathrm{NMR}\left(125.8 \mathrm{MHz}, \mathrm{CDCl}_{3}\right) \delta$ (ppm): 13.9, 19.8, 19.9, 24.2, 32.7, 33.0, 38.5, 47.7, 62.5, 73.3. Anal. calcd for $\mathrm{C}_{10} \mathrm{H}_{18} \mathrm{O}_{2}$ : C 70.55; $\mathrm{H}$ 10.66. Found: C 70.48; $\mathrm{H} 10.79$.

Synthesis of (1R,3S,5R)-3-benzyloxy-1-isopropyl-4-methylenebicyclo[3.1.0]hexane (12). To a stirred suspension of $\mathrm{NaH}(6 \mathrm{mmoL})$ in dry, freshly distilled THF $(10 \mathrm{~mL})$, a THF solution (3 mL) of 1 $(0.30 \mathrm{~g}, 2 \mathrm{mmoL})$ was added at room temperature under argon atmosphere. After $30 \mathrm{~min}$ stirring, a solution of benzyl bromide $(0.34 \mathrm{~g}, 2 \mathrm{mmoL})$ in THF $(3 \mathrm{~mL})$ was added dropwise at room temperature, and the reaction mixture was kept at boiling temperature for $1 \mathrm{~h}$. The reaction was quenched by the addition of $\mathrm{H}_{2} \mathrm{O}(2 \mathrm{~mL})$, and then THF was removed under reduced pressure to about $10 \%$ of the initial volume. After adding ice-cold water $(25 \mathrm{~mL})$ to the obtained residue, the aqueous phase was extracted with $\mathrm{CH}_{2} \mathrm{Cl}_{2}(4 \times 20 \mathrm{~mL})$, then the organic phase was dried $\left(\mathrm{Na}_{2} \mathrm{SO}_{4}\right)$, filtered and evaporated to dryness. The crude residue was purified by flash column chromatography on silica gel $\left(R_{\mathrm{f}}=0.80\right.$; n-hexane/EtOAc = 19:1).

Compound 12: $0.45 \mathrm{~g}(92 \%)$; pale-yellow oil; $[\alpha]_{\mathrm{D}}^{20}=+7(c=0.250 ; \mathrm{MeOH}) .{ }^{1} \mathrm{H}$ NMR $(500 \mathrm{MHz}$, $\left.\mathrm{CDCl}_{3}\right) \delta$ (ppm): 0.69-0.73 (1H, m), $0.87(3 \mathrm{H}, \mathrm{d}, J=6.9 \mathrm{~Hz}), 0.93(3 \mathrm{H}, \mathrm{d}, J=6.8 \mathrm{~Hz}), 1.18-1.21(1 \mathrm{H}, \mathrm{m})$, $1.46(1 \mathrm{H}$, septet, $J=6.8 \mathrm{~Hz}), 1.64(1 \mathrm{H}, \mathrm{dd}, J=2.4,8.5 \mathrm{~Hz}), 1.89(1 \mathrm{H}, \mathrm{d}, J=13.9 \mathrm{~Hz}), 2.05(1 \mathrm{H}, \mathrm{ddd}, J=1.4$, 7.3, $13.8 \mathrm{~Hz}), 4.08(1 \mathrm{H}, \mathrm{d}, J=7.2 \mathrm{~Hz}), 4.32(1 \mathrm{H}, \mathrm{d}, J=11.8 \mathrm{~Hz}), 4.57(1 \mathrm{H}, \mathrm{d}, J=11.7 \mathrm{~Hz}), 4.88(1 \mathrm{H}, \mathrm{s}), 5.11$ $(1 \mathrm{H}, \mathrm{s}), 7.27-7.39$ (5H, m). ${ }^{13} \mathrm{C} \mathrm{NMR}\left(125.8 \mathrm{MHz}, \mathrm{CDCl}_{3}\right) \delta$ (ppm): 18.6, 19.7, 19.8, 29.1, 32.6, 35.7, 36.7, $69.8,81.3,108.4,127.3,127.7,128.3,138.7,152.3$. Anal. calcd for $\mathrm{C}_{17} \mathrm{H}_{22} \mathrm{O}$ : C 84.25; $\mathrm{H}$ 9.15. Found: C 84.43; H 9.33.

\subsection{General Procedure for the Preparation of $\mathbf{1 3}$ and $\mathbf{1 4}$}

To a solution of 1 or $12(0.66 \mathrm{mmoL})$ in acetone $(5 \mathrm{~mL})$ 4-methylmorpholine $N$-oxide $(0.33 \mathrm{~mL}, 50 \%$ aqueous solution) and $\mathrm{OsO}_{4}(0.25 \mathrm{~mL}, 2 \%$ tert-BuOH solution) were added, and the reaction mixture was stirred for $24 \mathrm{~h}$ at room temperature. Then, the reaction was quenched by the addition of saturated aqueous $\mathrm{Na}_{2} \mathrm{SO}_{3}(5 \mathrm{~mL})$ and extracted with EtOAc $(3 \times 10 \mathrm{~mL})$. The organic layer was dried $\left(\mathrm{Na}_{2} \mathrm{SO}_{4}\right)$ and evaporated. The purification of the crude product was accomplished by column chromatography on silica gel $\left(13: \mathrm{R}_{\mathrm{f}}=0.15,14: \mathrm{R}_{\mathrm{f}}=0.40 ; n\right.$-hexane $/$ EtOAc $\left.=3 / 2\right)$.

(1R,2R,3S,5R)-2-Hydroxymethyl-5-isopropylbicyclo[3.1.0]hexane-2,3-diol (13): $0.10 \mathrm{~g}$ (81\%); white crystalline powder; mp: $148-150{ }^{\circ} \mathrm{C} ;[\alpha]_{\mathrm{D}}^{20}=+4(c=0.250 ; \mathrm{MeOH}) .{ }^{1} \mathrm{H} \mathrm{NMR}\left(500 \mathrm{MHz},\left(\mathrm{CD}_{3}\right)_{2} \mathrm{SO}\right) \delta(\mathrm{ppm})$ : $0.18-0.24(1 \mathrm{H}, \mathrm{m}), 0.82(3 \mathrm{H}, \mathrm{d}, J=6.8 \mathrm{~Hz}), 0.84(1 \mathrm{H}, \mathrm{t}, J=4.1 \mathrm{~Hz}), 0.90(3 \mathrm{H}, \mathrm{d}, J=6.8 \mathrm{~Hz}), 0.96-1.01(1 \mathrm{H}$, $\mathrm{m}), 1.34(1 \mathrm{H}$, septet, $J=6.8 \mathrm{~Hz}), 1.46(1 \mathrm{H}, \mathrm{d}, J=13.2 \mathrm{~Hz}), 2.09(1 \mathrm{H}, \mathrm{ddd}, J=1.0,6.6,13.0 \mathrm{~Hz}), 3.42(1 \mathrm{H}$, $\mathrm{dd}, J=6.3,11.0 \mathrm{~Hz}), 3.55(1 \mathrm{H}, \mathrm{dd}, J=5.4,11.0 \mathrm{~Hz}), 3.69-3.73(1 \mathrm{H}, \mathrm{m}), 4.08(1 \mathrm{H}, \mathrm{t}, J=5.8 \mathrm{~Hz}), 4.12(1 \mathrm{H}, \mathrm{s})$, $4.42(1 \mathrm{H}, \mathrm{d}, J=4.1 \mathrm{~Hz}) .{ }^{13} \mathrm{C} \mathrm{NMR}\left(125.8 \mathrm{MHz},\left(\mathrm{CD}_{3}\right)_{2} \mathrm{SO}\right) \delta(\mathrm{ppm}): 12.5,19.8,20.0,30.0,31.8,32.3,36.1$, 63.8, 76.9, 83.4. Anal. calcd for $\mathrm{C}_{10} \mathrm{H}_{18} \mathrm{O}_{3}$ : C 64.49; $\mathrm{H} 9.74$. Found: C 64.60; $\mathrm{H} 9.88$.

(1R,2R,3S,5R)-3-Benzyloxy-2-hydroxymethyl-5-isopropylbicyclo[3.1.0]hexan-2-ol (14): $0.08 \mathrm{~g}$ (44\%); colorless semi-solid; $[\alpha]_{\mathrm{D}}^{20}=+4(c=0.250 ; \mathrm{MeOH}) .{ }^{1} \mathrm{H}$ NMR $\left(500 \mathrm{MHz}, \mathrm{CDCl}_{3}\right) \delta(\mathrm{ppm}): 0.41-0.46(1 \mathrm{H}, \mathrm{m}), 0.90$ $(3 \mathrm{H}, \mathrm{d}, J=6.9 \mathrm{~Hz}), 0.94-0.97(1 \mathrm{H}, \mathrm{m}), 0.98(3 \mathrm{H}, \mathrm{d}, J=6.8 \mathrm{~Hz}), 1.04-1.08(1 \mathrm{H}, \mathrm{m}), 1.44(1 \mathrm{H}$, septet, $J=6.8$ $\mathrm{Hz}), 1.88(1 \mathrm{H}, \mathrm{d}, J=13.9 \mathrm{~Hz}), 2.11(1 \mathrm{H}, \mathrm{ddd}, J=1.6,6.6,13.9 \mathrm{~Hz}), 3.66(1 \mathrm{H}, \mathrm{d}, J=11.4 \mathrm{~Hz}), 3.73(1 \mathrm{H}, \mathrm{d}$, $J=6.5 \mathrm{~Hz}), 3.94(1 \mathrm{H}, \mathrm{d}, J=11.4 \mathrm{~Hz}), 4.27(1 \mathrm{H}, \mathrm{d}, J=11.8 \mathrm{~Hz}), 4.57(1 \mathrm{H}, \mathrm{d}, J=11.8 \mathrm{~Hz}), 7.26-7.37(5 \mathrm{H}$, m). ${ }^{13} \mathrm{C} \mathrm{NMR}\left(125.8 \mathrm{MHz}, \mathrm{CDCl}_{3}\right) \delta$ (ppm): 13.2, 19.9, 20.1, 29.3, 31.7, 32.2, 33.3, 65.2, 71.4, 85.1, 85.8, 127.5, 127.7, 128.5, 138.2. Anal. calcd for $\mathrm{C}_{17} \mathrm{H}_{24} \mathrm{O}_{3}$ : C 73.88; $\mathrm{H}$ 8.75. Found: C 73.99; $\mathrm{H} 8.84$. 


\subsection{General Procedure for the Preparation of $\mathbf{1 7}$ and $\mathbf{1 8}$}

Method $A$ : to a mixture of $\mathbf{1}(1.00 \mathrm{~g}, 6.57 \mathrm{mmoL})$ dissolved in $50 \mathrm{~mL} \mathrm{CH} \mathrm{Cl}_{2}$ and $\mathrm{Na}_{2} \mathrm{HPO}_{4} \cdot 12 \mathrm{H}_{2} \mathrm{O}$ $(3.40 \mathrm{~g}, 9.49 \mathrm{mmoL})$ dissolved in $100 \mathrm{~mL}$ water $(\mathrm{pH}=9.2), m$-chloroperbenzoic acid $(75 \%$ purity, $7.47 \mathrm{mmoL}$ ) was added in one portion at $0{ }^{\circ} \mathrm{C}$, and the mixture was stirred at room temperature. When the reaction was complete, as indicated by TLC $(1 \mathrm{~h})$, the mixture was separated, and the aqueous phase was extracted with $\mathrm{CH}_{2} \mathrm{Cl}_{2}(100 \mathrm{~mL})$. The organic layer was washed with $10 \% \mathrm{NaOH}$ solution $(3 \times 50 \mathrm{~mL})$, dried $\left(\mathrm{Na}_{2} \mathrm{SO}_{4}\right)$, and evaporated. The residue was purified by column chromatography on silica gel to afford a mixture of 17 and $18(0.78 \mathrm{~g}, 37 \%, \mathbf{1 7 : 1 8}=2: 1)$. Product $17(0.30 \mathrm{~g})$ was isolated in pure form by recrystallization from $\mathrm{CH}_{2} \mathrm{Cl}_{2} / n$-hexane.

Method $B$ : to a solution of $\mathbf{1}(0.50 \mathrm{~g}, 3.28 \mathrm{mmoL})$ in $25 \mathrm{~mL} \mathrm{CH} \mathrm{Cl}_{2}$ and $\mathrm{Na}_{2} \mathrm{HPO}_{4} \cdot 12 \mathrm{H}_{2} \mathrm{O}(1.70 \mathrm{~g}$, $4.74 \mathrm{mmoL})$ in $50 \mathrm{~mL}$ water $(\mathrm{pH}=9.2)$, a solution of $m$-chloroperbenzoic acid $(75 \%$ purity, $3.74 \mathrm{mmoL})$ in $\mathrm{CH}_{2} \mathrm{Cl}_{2}(25 \mathrm{~mL})$ was added dropwise over $10 \mathrm{~min}$ at $0{ }^{\circ} \mathrm{C}$, and the mixture was stirred at room temperature. When the reaction was complete, as indicated by TLC $(1 \mathrm{~h})$, the mixture was separated, and the aqueous phase was extracted with $\mathrm{CH}_{2} \mathrm{Cl}_{2}(50 \mathrm{~mL})$. The organic layer was washed with saturated aqueous solution of $\mathrm{NaHCO}_{3}(3 \times 50 \mathrm{~mL})$, dried $\left(\mathrm{Na}_{2} \mathrm{SO}_{4}\right)$, and evaporated to afford 18 as the single product.

((1R,2S,3S,5R)-2,3-dihydroxy-5-isopropylbicyclo[3.1.0]hexan-2-yl)methyl 3-chlorobenzoate (17). Method A, $0.30 \mathrm{~g}\left(14 \%\right.$, in isolated pure form); white crystals; mp: $93-96{ }^{\circ} \mathrm{C} ;[\alpha]_{\mathrm{D}}^{20}=+22(c=0.250 ; \mathrm{MeOH}) .{ }^{1} \mathrm{H}$ NMR (500 MHz, $\left.\mathrm{CDCl}_{3}\right) \delta(\mathrm{ppm}): 0.48-0.52(1 \mathrm{H}, \mathrm{m}), 0.87(3 \mathrm{H}, \mathrm{d}, J=6.9 \mathrm{~Hz}), 0.92(3 \mathrm{H}, \mathrm{d}, J=6.8 \mathrm{~Hz})$, $1.16(1 \mathrm{H}, \mathrm{t}, J=4.2 \mathrm{~Hz}), 1.30-1.37(2 \mathrm{H}, \mathrm{m}), 1.89(1 \mathrm{H}, \mathrm{d}, J=14.3 \mathrm{~Hz}), 2.10(1 \mathrm{H}, \mathrm{ddd}, J=1.1,7.0,14.2 \mathrm{~Hz})$, $2.54(1 \mathrm{H}$, br s), $2.81(1 \mathrm{H}$, br s), $3.95(1 \mathrm{H}, \mathrm{d}, J=7.0 \mathrm{~Hz}), 4.30(1 \mathrm{H}, \mathrm{d}, J=11.6 \mathrm{~Hz}), 4.39(1 \mathrm{H}, \mathrm{d}, J=11.6$ $\mathrm{Hz}), 7.40(1 \mathrm{H}, \mathrm{t}, J=7.9 \mathrm{~Hz}), 7.55(1 \mathrm{H}, \mathrm{d}, J=8.0 \mathrm{~Hz}), 7.96(1 \mathrm{H}, \mathrm{d}, J=7.9 \mathrm{~Hz}), 8.04(1 \mathrm{H}, \mathrm{s}) .{ }^{13} \mathrm{C} \mathrm{NMR}$ $\left(125.8 \mathrm{MHz}_{,} \mathrm{CDCl}_{3}\right) \delta(\mathrm{ppm}):$ 13.7, 19.5, 19.7, 29.5, 32.4, 32.8, 35.2, 69.4, 72.9, 80.7, 127.9, 129.8, 129.8, 131.5, 133.3, 134.7, 165.6. Anal. calcd for $\mathrm{C}_{17} \mathrm{H}_{21} \mathrm{ClO}_{4}$ : C 62.86; H 6.52. Found: C 63.01; H 6.60.

(1R,3S,4S,5R)-4-Hydroxy-4-hydroxymethyl-1-isopropylbicyclo[3.1.0]hexan-3-yl 3-chlorobenzoate (18). Method $\mathrm{B}, 0.40 \mathrm{~g}(38 \%)$; white crystalline powder; mp: $110-112{ }^{\circ} \mathrm{C} ;[\alpha]_{\mathrm{D}}^{20}=+12(c=0.250 ; \mathrm{MeOH}) .{ }^{1} \mathrm{H} \mathrm{NMR}$ $\left(400 \mathrm{MHz} \mathrm{CDCl}_{3}\right) \delta(\mathrm{ppm}): 0.55-0.61(1 \mathrm{H}, \mathrm{m}), 0.91(3 \mathrm{H}, \mathrm{d}, J=6.9 \mathrm{~Hz}), 0.95(3 \mathrm{H}, \mathrm{d}, J=6.8 \mathrm{~Hz}), 1.23$ $(1 \mathrm{H}, \mathrm{t}, J=4.4 \mathrm{~Hz}), 1.38(1 \mathrm{H}$, septet, $J=6.8 \mathrm{~Hz}), 1.75(1 \mathrm{H}, \mathrm{dd}, J=3.7,8.6 \mathrm{~Hz}), 1.87(1 \mathrm{H}, \mathrm{d}, J=14.1 \mathrm{~Hz})$, $2.16(1 \mathrm{H}, \mathrm{ddd}, J=1.5,7.2,14.2 \mathrm{~Hz}), 2.19(1 \mathrm{H}, \mathrm{br} \mathrm{s}), 3.03(1 \mathrm{H}$, br s) $, 3.83(1 \mathrm{H}, \mathrm{d}, J=12.6 \mathrm{~Hz}), 3.96(1 \mathrm{H}$, $\mathrm{d}, J=12.6 \mathrm{~Hz}), 4.37(1 \mathrm{H}, \mathrm{d}, J=7.0 \mathrm{~Hz}), 7.40(1 \mathrm{H}, \mathrm{t}, J=7.9 \mathrm{~Hz}), 7.55(1 \mathrm{H}, \mathrm{d}, J=8.0 \mathrm{~Hz}), 7.91(1 \mathrm{H}, \mathrm{d}$, $J=7.8 \mathrm{~Hz}), 8.00(1 \mathrm{H}, \mathrm{s}) .{ }^{13} \mathrm{C}$ NMR $\left(125.8 \mathrm{MHz}, \mathrm{CDCl}_{3}\right) \delta(\mathrm{ppm}): 15.1,19.9,20.0,27.7,32.9,33.2,35.2$, $66.9,73.7,94.0,128.3,130.2,132.6,133.8,134.3,135.1,166.8$. Anal. calcd for $\mathrm{C}_{17} \mathrm{H}_{21} \mathrm{ClO}_{4}$ : C 62.86; $\mathrm{H} 6.52$. Found: C 62.97; H 6.75 .

Synthesis of $(1 R, 2 S, 3 S, 5 R)-2-h y d r o x y m e t h y l-5-i s o p r o p y l b i c y c l o[3.1 .0] h e x a n e-2,3-d i o l$ (19). To a solution of 17 or 18 (33 mg, $0.10 \mathrm{mmoL})$ in $\mathrm{EtOH}(2 \mathrm{~mL})$, a $10 \%$ cold aqueous solution of $\mathrm{NaOH}(1 \mathrm{~mL})$ was added at room temperature. The reaction mixture was stirred for $30 \mathrm{~min}$, then concentrated under reduced pressure to evaporate ethanol, and the aqueous residue was extracted with $\mathrm{CH}_{2} \mathrm{Cl}_{2}(3 \times 3 \mathrm{~mL})$. The combined organic extract was washed with brine, dried $\left(\mathrm{Na}_{2} \mathrm{SO}_{4}\right)$ and evaporated.

Compound 19: $17 \mathrm{mg}$ (91\%); white crystalline powder; $\mathrm{mp}: 90-92{ }^{\circ} \mathrm{C} ;[\alpha]_{\mathrm{D}}^{20}=+45(c=0.250$; $\mathrm{MeOH}) .{ }^{1} \mathrm{H}$ NMR $\left(500 \mathrm{MHz},\left(\mathrm{CD}_{3}\right)_{2} \mathrm{SO}\right) \delta(\mathrm{ppm}): 0.22-0.26(1 \mathrm{H}, \mathrm{m}), 0.80(3 \mathrm{H}, \mathrm{d}, J=6.8 \mathrm{~Hz}), 0.85(3 \mathrm{H}$, $\mathrm{d}, J=6.8 \mathrm{~Hz}), 0.94(1 \mathrm{H}, \mathrm{t}, J=3.9 \mathrm{~Hz}), 1.03(1 \mathrm{H}, \mathrm{dd}, J=3.5,8.5 \mathrm{~Hz}), 1.23(1 \mathrm{H}$, septet, $J=6.8 \mathrm{~Hz}), 1.55$ $(1 \mathrm{H}, \mathrm{d}, J=13.6 \mathrm{~Hz}), 1.89(1 \mathrm{H}, \mathrm{ddd}, J=1.0,7.1,13.6 \mathrm{~Hz}), 3.21(1 \mathrm{H}, \mathrm{dd}, J=6.4,11.1 \mathrm{~Hz}), 3.33(1 \mathrm{H}, \mathrm{dd}$, $J=5.6,11.1 \mathrm{~Hz}), 3.64-3.68(1 \mathrm{H}, \mathrm{m}), 3.95(1 \mathrm{H}, \mathrm{s}), 4.44(1 \mathrm{H}, \mathrm{d}, J=3.8), 4.55(1 \mathrm{H}, \mathrm{t}, J=5.9 \mathrm{~Hz}) .{ }^{13} \mathrm{C} \mathrm{NMR}$ $\left(125.8 \mathrm{MHz},\left(\mathrm{CD}_{3}\right)_{2} \mathrm{SO}\right) \delta$ (ppm): 13.2, 19.4, 19.5, 29.2, 31.2, 32.0, 35.0, 66.8, 71.1, 80.8. Anal. calcd for $\mathrm{C}_{10} \mathrm{H}_{18} \mathrm{O}_{3}$ : C 64.49; $\mathrm{H} 9.74$. Found: C 64.69; $\mathrm{H} 9.83$. 


\subsection{General Procedure for the Reaction of Aldehydes with Diethylzinc in the Presence of Chiral Catalyst}

To the respective catalyst $(0.1 \mathrm{mmoL}), 1 \mathrm{M} \mathrm{Et}_{2} \mathrm{Zn}$ in $n$-hexane solution $(3 \mathrm{~mL}, 3 \mathrm{mmoL})$ was added under an Ar atmosphere at room temperature. The reaction was stirred for $25 \mathrm{~min}$ at room temperature (see Table 1$)$, and benzaldehyde $(1 \mathrm{mmoL})$ was then added to the solution with subsequent stirring at room temperature (see Table 1 ) for a further $20 \mathrm{~h}$. The reaction was quenched with a saturated $\mathrm{NH}_{4} \mathrm{Cl}$ solution $(15 \mathrm{~mL})$, and the mixture was extracted with EtOAc $(2 \times 20 \mathrm{~mL})$. The combined organic phase was washed with $\mathrm{H}_{2} \mathrm{O}(10 \mathrm{~mL})$, dried $\left(\mathrm{Na}_{2} \mathrm{SO}_{4}\right)$, and evaporated under vacuum. The crude secondary alcohols obtained were purified by flash column chromatography $\left(\mathrm{R}_{\mathrm{f}}=0.54 ; n\right.$-hexane $/$ EtOAc $\left.=4 / 1\right)$. The ee and absolute configuration of the resulting material were determined by chiral HPLC analysis on a Chiralcel OD-H column and the data are as follows: 1-phenyl-1-propanol; $V$ ( $n$-hexane)/ $V$ (2-propanol) $=95: 5,0.7 \mathrm{~mL} / \mathrm{min}, 215 \mathrm{~nm}, t_{\mathrm{R} 1}=6.29 \mathrm{~min}$ for $R$-isomer, $t_{\mathrm{R} 2}=6.73 \mathrm{~min}$ for $S$-isomer [7].

\subsection{X-Ray Structure Determination of $\mathbf{1 1}$}

Single crystals of 11 were grown by warming up 11 in heptane until almost full dissolution, and then the solution was abruptly cooled in an ice bath. X-ray intensity data were collected at $-123{ }^{\circ} \mathrm{C}$ on a Rigaku UltraX $18 S$ generator (Xenocs mirrors, Mo K $\alpha$ radiation, $\lambda=0.71073 \AA$ ) using a MAR345 image plate. The images were interpreted and integrated with CrysAlisPRO [48], and the implemented absorption correction was applied. Using Olex2 [49], the structures were solved with the ShelXS [50] structure solution program by Direct Methods, and refined with the ShelXL [51] refinement package using full-matrix least-squares minimization on $F^{2}$. Non-hydrogen atoms were refined anisotropically, and hydrogen atoms in the riding mode with isotropic temperature factors fixed at 1.2 times $U_{\text {eq }}$ of the parent atoms (1.5 for the $-\mathrm{CH}_{3}$ and the $-\mathrm{OH}$ groups). Because compound 11 is composed of only light atoms $(\mathrm{C}, \mathrm{H}, \mathrm{O})$, it was not possible to determine its absolute configuration. CCDC number 1814013 contains the supplementary crystallographic data.

Crystal Data for $\mathrm{C}_{10} \mathrm{H}_{18} \mathrm{O}_{2}(M=170.24 \mathrm{~g} / \mathrm{moL})$ : orthorhombic, space group $P 2{ }_{1} 2_{1} 2_{1}$ (no. 19), $a=6.1474(2) \AA, b=8.1525(3) \AA, c=19.6783(6) \AA, V=986.21(6) \AA^{3}, Z=4, T=150.15 \mathrm{~K}$, $\mu(\operatorname{MoK} \alpha)=0.078 \mathrm{~mm}^{-1}$, Dcalc $=1.147 \mathrm{~g} / \mathrm{cm}^{3}, 8206$ reflections measured $\left(10.216^{\circ} \leq 2 \theta \leq 52.006^{\circ}\right)$, 1915 unique $\left(R_{\text {int }}=0.0310, R_{\text {sigma }}=0.0189\right)$ which were used in all calculations. The final $R_{1}$ was 0.0328 $(\mathrm{I}>2 \sigma(\mathrm{I}))$ and $w R_{2}$ was 0.0848 (all data).

\section{Conclusions}

In conclusion, we have developed a library of new chiral sabinol-based aminodiol, diol, and triol derivatives (6-19). Our results revealed that functionalization of (+)-sabinol occurred with high stereoselectivity, affording only a single diastereomeric product in each case. Stereoselectivities, however, were found to be lower as compared with other monoterpene-based trifunctional catalysts. It is surmised that, because of the appreciable steric influence of the bicyclic ring system and the freely rotating hydroxymethyl or aminomethyl group, a stable transition state could not be formed in the reactions of the applied catalysts and $\mathrm{Et}_{2} \mathrm{Zn}$. From this point of view, aminodiols have proven to be more efficient catalysts compared to diol or triol derivatives.

On the other hand, because of the observed different reactivity of the functional groups (caused by the steric hindrance of the bicyclic system of sabinane skeleton), the obtained aminodiols, diols, and triols may serve as useful building blocks for the synthesis of new heterocyclic ring systems and biologically active compounds.

Supplementary Materials: The following are available online at http:/ / www.mdpi.com/1420-3049/23/4/771/s1, ${ }^{1} \mathrm{H},{ }^{13} \mathrm{C}$ NMR, HSQC, HMBC, COSY, and NOESY spectra of new compounds (S3-S24) and crystal structure of diol 11 (S25).

Acknowledgments: Z.S. is grateful for financial support from the Hungarian Research Foundation (OTKA K112442) and for the EU-funded Hungarian grant GINOP-2.3.2-15-2016-00012. 
Author Contributions: The listed authors contributed to this work as described in the following. Zsolt Szakonyi, Wim Dehaen and Yerlan M. Suleimen designed, planed research, interpreted the results. Yerbolat Tashenov and Mathias Daniels planed research, interpreted the results and carried out of the synthetic work. Koen Robeyns and Luc Van Meervelt performed X-ray experiments. All authors discussed the results, prepared and commented on the manuscript.

Conflicts of Interest: The authors declare no conflict of interest.

\section{References}

1. Berkessel, A.; Gröger, H. Asymmetric Organocatalysis: From Biomimetic Concepts to Applications in Asymmetric Synthesis; Wiley-VCH: Weinheim, Germany, 2005; ISBN 978-3-527-30517-9.

2. Dalko, P.I. (Ed.) Enantioselective Organocatalysis; Wiley-VCH Verlag GmbH \& Co. KGaA: Weinheim, Germany, 2007; ISBN 978-3-527-61094-5.

3. Lin, G.-Q.; You, Q.-D.; Cheng, J.-F. (Eds.) Chiral Drugs: Chemistry and Biological Action; Wiley: Hoboken, NJ, USA, 2011; ISBN 978-0-470-58720-1.

4. Carreira, E.M.; Yamamoto, H. Comprehensive Chirality; Elsevier: Oxford, UK, 2012; ISBN 978-0-08-095168-3.

5. El Alami, M.S.I.; El Amrani, M.A.; Agbossou-Niedercorn, F.; Suisse, I.; Mortreux, A. Chiral Ligands Derived from Monoterpenes: Application in the Synthesis of Optically Pure Secondary Alcohols via Asymmetric Catalysis. Chem. Eur. J. 2015, 21, 1398-1413. [CrossRef] [PubMed]

6. Andrés, C.; González, I.; Nieto, J.; Rosón, C.D. Lewis acid mediated diastereoselective keto-ene cyclization on chiral perhydro-1,3-benzoxazines: Synthesis of enantiopure cis-3,4-disubstituted 3-hydroxypyrrolidines. Tetrahedron 2009, 65, 9728-9736. [CrossRef]

7. Andrés, C.; Infante, R.; Nieto, J. Perhydro-1,3-benzoxazines derived from (-)-8-aminomenthol as ligands for the catalytic enantioselective addition of diethylzinc to aldehydes. Tetrahedron Asymmetry 2010, 21, 2230-2237. [CrossRef]

8. Gonda, T.; Szakonyi, Z.; Csámpai, A.; Haukka, M.; Fülöp, F. Stereoselective synthesis and application of tridentate aminodiols derived from (+)-pulegone. Tetrahedron Asymmetry 2016, 27, 480-486. [CrossRef]

9. Hobuß, D.; Hasenjäger, J.; Driessen-Hölscher, B.; Baro, A.; Axenov, K.V.; Laschat, S.; Frey, W. Novel $\alpha$-pinene-derived mono- and bisphosphinite ligands: Synthesis and application in catalytic hydrogenation. Inorg. Chim. Acta 2011, 374, 94-103. [CrossRef]

10. Szakonyi, Z.; Balázs, Á.; Martinek, T.A.; Fülöp, F. Enantioselective addition of diethylzinc to aldehydes catalyzed by $\gamma$-amino alcohols derived from (+)- and (-)- $\alpha$-pinene. Tetrahedron Asymmetry 2006, 17, $199-204$. [CrossRef]

11. Csillag, K.; Németh, L.; Martinek, T.A.; Szakonyi, Z.; Fülöp, F. Stereoselective synthesis of pinane-type tridentate aminodiols and their application in the enantioselective addition of diethylzinc to benzaldehyde. Tetrahedron Asymmetry 2012, 23, 144-150. [CrossRef]

12. Zielińska-Błajet, M.; Rewucki, P.; Walenczak, S. Sulfur-containing derivatives from (1R)-(-)-myrtenal designed as chiral ligands. Tetrahedron 2016, 72, 3851-3857. [CrossRef]

13. Yang, J.; Xu, H.; Xu, X.; Rui, J.; Fang, X.; Cao, X.; Wang, S. Synthesis, optical properties, and cellular imaging of novel quinazolin-2-amine nopinone derivatives. Dyes Pigment. 2016, 128, 75-83. [CrossRef]

14. Yang, J.; Xu, X.; Rui, J.; Wang, Z.; Zhang, Y.; Wang, S.; Wu, L. Synthesis, optical properties and application of a set of novel pyrazole nopinone derivatives. Spectrochim. Acta Part A Mol. Biomol. Spectrosc. 2017, 183, 60-67. [CrossRef] [PubMed]

15. Dickmu, G.C.; Smoliakova, I.P. Preparation and characterization of cyclopalladated complexes derived from 1-(-)-fenchone. J. Organomet. Chem. 2014, 772-773, 42-48. [CrossRef]

16. De las Casas Engel, T.; Maroto, B.L.; Martínez, A.G.; de la Moya Cerero, S. N/N/O versus N/O/O and $\mathrm{N} / \mathrm{O}$ amino isoborneols in the enantioselective ethylation of benzaldehyde. Tetrahedron Asymmetry 2008, 19, 269-272. [CrossRef]

17. Sánchez-Carnerero, E.M.; de las Casas Engel, T.; Maroto, B.L.; de la Moya Cerero, S. Polyoxygenated ketopinic-acid-derived $\gamma$-amino alcohols in the enantioselective diethylzinc addition to benzaldehyde. Tetrahedron Asymmetry 2009, 20, 2655-2657. [CrossRef]

18. García Martínez, A.; Teso Vilar, E.; García Fraile, A.; de la Moya Cerero, S.; Lora Maroto, B. Synthesis and catalytic activity of 10-(aminomethyl)isoborneol-based catalysts: The role of the C(2)-group on the asymmetric induction. Tetrahedron Asymmetry 2003, 14, 1959-1963. [CrossRef] 
19. Stoyanova, M.P.; Shivachev, B.L.; Nikolova, R.P.; Dimitrov, V. Highly efficient synthesis of chiral aminoalcohols and aminodiols with camphane skeleton. Tetrahedron Asymmetry 2013, 24, 1426-1434. [CrossRef]

20. Lait, S.M.; Rankic, D.A.; Keay, B.A. 1,3-Aminoalcohols and Their Derivatives in Asymmetric Organic Synthesis. Chem. Rev. 2007, 107, 767-796. [CrossRef] [PubMed]

21. Fülöp, F.; Bernáth, G.; Pihlaja, K. Synthesis, Stereochemistry and Transformations of Cyclopentane-, Cyclohexane-, Cycloheptane-, and Cyclooctane-Fused 1,3-Oxazines, 1,3-Thiazines, and Pyrimidines. Adv. Heterocycl. Chem. 1997, 69, 349-477.

22. Lázár, L.; Fülöp, F. 1,3-Oxazines and their Benzo Derivatives. Compr. Heterocycl. Chem. III 2008, 373-459. [CrossRef]

23. Szakonyi, Z.; Hetényi, A.; Fülöp, F. Synthesis of enantiomeric spirooxazolines and spirooxazolidines by the regioselective ring closure of (-)- $\alpha$-pinene-based aminodiols. Arkivoc 2007, 33-42. [CrossRef]

24. Szakonyi, Z.; Csillag, K.; Fülöp, F. Stereoselective synthesis of carane-based aminodiols as chiral ligands for the catalytic addition of diethylzinc to aldehydes. Tetrahedron Asymmetry 2011, 22, 1021-1027. [CrossRef]

25. Szakonyi, Z.; Csőrr, Á.; Csámpai, A.; Fülöp, F. Stereoselective Synthesis and Modelling-Driven Optimisation of Carane-Based Aminodiols and 1,3-Oxazines as Catalysts for the Enantioselective Addition of Diethylzinc to Benzaldehyde. Chem. Eur. J. 2016, 22, 7163-7173. [CrossRef] [PubMed]

26. Kleinert, H.; Rosenberg, S.; Baker, W.; Stein, H.; Klinghofer, V.; Barlow, J.; Spina, K.; Polakowski, J.; Kovar, P.; Cohen, J.; et al. Discovery of a peptide-based renin inhibitor with oral bioavailability and efficacy. Science 1992, 257, 1940-1943. [CrossRef] [PubMed]

27. Jaime-Figueroa, S.; Greenhouse, R.; Padilla, F.; Dillon, M.P.; Gever, J.R.; Ford, A.P.D.W. Discovery and synthesis of a novel and selective drug-like P2X1 antagonist. Bioorg. Med. Chem. Lett. 2005, 15, 3292-3295. [CrossRef] [PubMed]

28. Grajewska, A.; Rozwadowska, M.D. Stereoselective synthesis of cytoxazone and its analogues. Tetrahedron Asymmetry 2007, 18, 803-813. [CrossRef]

29. Narina, S.V.; Kumar, T.S.; George, S.; Sudalai, A. Enantioselective synthesis of (-)-cytoxazone and (+)-epi-cytoxazone via Rh-catalyzed diastereoselective oxidative $\mathrm{C}-\mathrm{H}$ aminations. Tetrahedron Lett. 2007, 48, 65-68. [CrossRef]

30. Kakeya, H.; Morishita, M.; Koshino, H.; Morita, T.; Kobayashi, K.; Osada, H. Cytoxazone: A Novel Cytokine Modulator Containing a 2-Oxazolidinone Ring Produced by Streptomyces sp. J. Org. Chem. 1999, 64, 1052-1053. [CrossRef]

31. Paraskar, A.S.; Sudalai, A. Enantioselective synthesis of (-)-cytoxazone and (+)-epi-cytoxazone, novel cytokine modulators via Sharpless asymmetric epoxidation and 1-proline catalyzed Mannich reaction. Tetrahedron 2006, 62, 5756-5762. [CrossRef]

32. Zhu, W.; Burnette, A.; Dorjsuren, D.; Roberts, P.E.; Huleihel, M.; Shoemaker, R.H.; Marquez, V.E.; Agbaria, R.; Sei, S. Potent Antiviral Activity of North-Methanocarbathymidine against Kaposi's Sarcoma-Associated Herpesvirus. Antimicrob. Agents Chemother. 2005, 49, 4965-4973. [CrossRef] [PubMed]

33. Roy, C.D.; Brown, H.C. A Study of Transesterification of Chiral (-)-Pinanediol Methylboronic Ester with Various Structurally Modified Diols. Monatshefte Für Chem. Chem. Mon. 2007, 138, 747-753. [CrossRef]

34. Cherng, Y.-J.; Fang, J.-M.; Lu, T.-J. Pinane-Type Tridentate Reagents for Enantioselective Reactions: Reduction of Ketones and Addition of Diethylzinc to Aldehydes. J. Org. Chem. 1999, 64, 3207-3212. [CrossRef] [PubMed]

35. Ardashov, O.V.; Pavlova, A.V.; Il'ina, I.V.; Morozova, E.A.; Korchagina, D.V.; Karpova, E.V.; Volcho, K.P.; Tolstikova, T.G.; Salakhutdinov, N.F. Highly Potent Activity of (1R,2R,6S)-3-Methyl-6-(prop-1-en-2-yl)cyclohex3-ene-1,2-diol in Animal Models of Parkinson's Disease. J. Med. Chem. 2011, 54, 3866-3874. [CrossRef] [PubMed]

36. Radulović, N.S.; Mladenović, M.Z.; Randjelovic, P.J.; Stojanović, N.M.; Dekić, M.S.; Blagojević, P.D. Toxic essential oils. Part IV: The essential oil of Achillea falcata L. as a source of biologically/pharmacologically active trans-sabinyl esters. Food Chem. Toxicol. 2015, 80, 114-129. [CrossRef]

37. Tuberoso, C.I.G.; Kowalczyk, A.; Coroneo, V.; Russo, M.T.; Dessì, S.; Cabras, P. Chemical Composition and Antioxidant, Antimicrobial, and Antifungal Activities of the Essential Oil of Achillea ligustica All. J. Agric. Food Chem. 2005, 53, 10148-10153. [CrossRef] [PubMed]

38. Rudloff, E.V. Gas-Liquid Chromatography of Terpenes: Part ix. the Volatile Oil of the Leaves of Juniperus Sabina L. Can. J. Chem. 1963, 41, 2876-2881. [CrossRef] 
39. Banthorpe, D.; Davies, H.; Gatford, C.; Williams, S. Monoterpene Patterns in Juniperus and Thuja Species. Planta Med. 1973, 23, 64-69. [CrossRef] [PubMed]

40. Fournier, G.; Pages, N.; Fournier, C.; Callen, G. Contribution to the Study of the Essential Oil of Various Cultivars of Juniperus sabina. Planta Med. 1991, 57, 392-393. [CrossRef] [PubMed]

41. Suleimenov, E.M.; Raldugin, V.A.; Shakirov, M.M.; Bagryanskaya, I.Y.; Gatilov, Y.V.; Kulyjiasov, A.T.; Adekenov, S.M. [4+2]-Cyclodimer of sabinone: Formation, crystal structure, and NMR spectra. Russ. Chem. Bull. 2003, 52, 1210-1212. [CrossRef]

42. Fernandes, R.A.; Kattanguru, P.; Gholap, S.P.; Chaudhari, D.A. Recent advances in the Overman rearrangement: Synthesis of natural products and valuable compounds. Org. Biomol. Chem. 2017, 15, 2672-2710. [CrossRef] [PubMed]

43. Becerra-Martínez, E.; Ayala-Mata, F.; Velázquez-Ponce, P.; Medina, M.E.; Jiménez-Vazquez, H.A.; Joseph-Nathan, P.; Zepeda, L.G. Nucleophilic additions on acetyldioxanes derived from (-)-(1R)-myrtenal used as chiral auxiliaries: Substituent effects on the stereochemical outcome. Tetrahedron Asymmetry 2017, 28, 1350-1358. [CrossRef]

44. Chen, X.; Gu, W.; Jing, X.; Pan, X. A New Approach for Synthesis of Erythro 8-O-4' Neolignans. Synth. Commun. 2002, 32, 557-564. [CrossRef]

45. Fang, W.; Wei, Y.; Tang, X.-Y.; Shi, M. Gold(I)-Catalyzed Cycloisomerization of ortho-(Propargyloxy) arenemethylenecyclopropanes Controlled by Adjacent Substituents at Aromatic Rings. Chem. Eur. J. 2017, 23, 6845-6852. [CrossRef] [PubMed]

46. Hurlocker, B.; Hu, C.; Woerpel, K.A. Structure and Reactivity of an Isolable Seven-Membered-Ring trans-Alkene. Angew. Chem. Int. Ed. 2015, 54, 4295-4298. [CrossRef] [PubMed]

47. Garside, P.; Halsall, T.G.; Hornby, G.M. Action of peracetic acid on (+)-sabinol. J. Chem. Soc. C Org. 1969, 716-721. [CrossRef]

48. CrysAlis PRO; Agilent Technologies UK Ltd.: Oxfordshire, UK, 2012.

49. Dolomanov, O.V.; Bourhis, L.J.; Gildea, R.J.; Howard, J.A.K.; Puschmann, H. OLEX2: A complete structure solution, refinement and analysis program. J. Appl. Crystallogr. 2009, 42, 339-341. [CrossRef]

50. Sheldrick, G.M. A short history of SHELX. Acta Crystallogr. A 2008, 64, 112-122. [CrossRef] [PubMed]

51. Sheldrick, G.M. Crystal structure refinement with SHELXL. Acta Crystallogr. Sect. C Struct. Chem. 2015, 71, 3-8. [CrossRef] [PubMed]

Sample Availability: Samples of the compounds 3-17 are available from the authors.

(C) 2018 by the authors. Licensee MDPI, Basel, Switzerland. This article is an open access article distributed under the terms and conditions of the Creative Commons Attribution (CC BY) license (http:/ / creativecommons.org/licenses/by/4.0/). 